\title{
Association between Ischemic Electrocardiographic Changes during Acetylcholine Provocation Test and Long-Term Clinical Outcomes in Patients with Vasospastic Angina
}

Sung Il Im², Seung-Woon Rha², Byoung Geol Choi ${ }^{2}$, Jin Oh $\mathrm{Na}^{2}$, Cheol Ung $\mathrm{Choi}^{2}$, Hong Euy Lim², Jin Won $\mathrm{Kim}^{2}$, Eung Ju Kim², Chang Gyu Park², Hong Seog Seo

${ }^{1}$ Division of Cardiology, Department of Internal Medicine, Kosin University Gospel Hospital, Busan, Korea ${ }^{2}$ Division of Cardiology, Department of Internal Medicine, Cardiovascular Center, Korea University Guro Hospital, Seoul, Korea

Objectives: Intracoronary injection of acetylcholine (Ach) has been shown to induce significant coronary artery spasm (CAS) in patients with vasospastic angina. Clinical significance and angiographic characteristics of patients with ischemic electrocardiogram (ECG) changes during the Ach provocation test are not clarified yet.

Methods: A total 4,418 consecutive patients underwent coronary angiography with Ach provocation tests from 2004 to 2012 were enrolled. Ischemic ECG changes were defined as transient ST-segment depression or elevation ( $>1 \mathrm{~mm}$ ) and $\mathrm{T}$ inversion with/without chest pain. Finally, a total 2,293 patients (28.5\% of total subjects) proven CAS were enrolled for this study.

Results: A total 119 patients (5.2\%) showed ECG changes during Ach provocation tests. The baseline clinical and procedural characteristics are well balanced between the two groups. Ischemic ECG change group showed more frequent chest pain, higher incidence of baseline spasm, severe vasospasm, multi-vessel involvement, and more diffuse spasm ( $>30 \mathrm{~mm}$ ) than those without ischemic ECG changes. At 5 years, the incidences of death, major adverse cardiac events (MACE) and major adverse cardiac and cerebral events (MACCE) were higher in the ischemic ECG change group despite of optimal medical therapy.

Conclusions: The patients with ischemic ECG changes during Ach provocation tests were associated with more frequent chest pain, baseline spasm, diffuse, severe and multi-vessel spasm than patients without ischemic ECG changes. At 5-years, the incidences of death, MACE and MACCE were higher in the ischemic ECG change group, suggesting more intensive medical therapy with close clinical follow up will be required.

Key Words: Acetylcholine, Electrocardiogram, Vasospastic angina

Recent studies have shown that approximately $40 \%$ of patients undergoing diagnostic coronary angiography (CAG) for typical exertional chest pain have completely normal arteries or non-ob-
Corresponding Author: Seung-Woon Rha, Division of Cardiology, Department of Internal Medicine, Cardiovascular Center, Korea University Guro Hospital, 148, Guro-dong-ro, Guro-gu, Seoul 08308, Korea Tel: +82-2-2626-3020 Fax: +82-2-864-3062 E-mail: swrha617@yahoo.co.kr

\section{(c) (1) (3)}

Articles published in Kosin Medical Journal are open-access, distributed under the terms of the Creative Commons Attribution Non-Commercial License (http://creativecommons.org/licenses/by-nc/4.0/) which permits unrestricted non-commercial use, distribution, and reproduction in any medium, provided the original work is properly cited.
Received: Feb. 12, 2018

Revised: $\quad$ May. 09, 2018

Accepted: May. 21, 2018 
structive coronary artery disease (CAD). ${ }^{1-3}$ The normal CAG often leads the managing physician to make a diagnosis of non-cardiac chest pain. However, in this situation, intracoronary injection of acetylcholine (Ach) during CAG is useful for induction of significant coronary artery spasm (CAS) in patients with vasospastic angina. Recently, instead of intravenous administration of ergonovine, intracoronary Ach testing has been employed in the clinical setting. Previous study reported that the spasm provocation test with Ach has an acceptable level of safety, and the evaluation of spasm type may provide useful information for the risk stratification of CAS. ${ }^{4}$ The coronary arteries of patients with vasospastic angina are hyper-reactive to diverse constrictor stimuli and occlusive constriction is readily induced by exposure to such a stimulus. The vascular effects of Ach on human coronary arteries are complex. ${ }^{5}$ Our previous study reported that clinical and angiographic characteristics of Ach induced spasm were related to dose of intracoronary injection of Ach in patients with vasospastic angina. ${ }^{6}$ However, clinical significance and angiographic characteristics of patients with vasospastic angina according to the ischemic electrocardiographic (ECG) changes during Ach provocation test are not clarified yet. In this study, we sought to clarify the impact of ischemic ECG changes during the Ach provocation test on clinical outcomes in patients with vasospastic angina during 5 years follow-up.

\section{MATERIALS AND METHODS}

\section{Study population}

We performed CAG in 8,052 consecutive patients (male $50.5 \%$, mean age $54.6 \pm 11.5$ years) who had typical or atypical chest pain to diagnose or exclude significant $\mathrm{CAD}$ at cardiovascular center in Korea University Guro Hospital, Seoul, South Korea. Among them, 4,418 patients who had chest pain without significant coronary lesion [less than $50 \%$ of fixed stenosis on quantitative coronary angiography (QCA)] underwent CAG with intracoronary Ach provocation test. The patients were excluded if they had one of the following conditions including prior coronary artery bypass graft $(\mathrm{CABG})$, prior percutaneous coronary intervention (PCI), prior cerebrovascular disease (CVD), advanced heart failure (New York Heart Association class III or IV), or serum creatinine $\geq 3 \mathrm{mg} / \mathrm{dL}$, because these conditions can be major causes of adverse cardiovascular events and could serve as the bias of CAS. Finally, a total 2,293 patients $(28.5 \%$ of total subjects underwent CAG) who showed angiographic proven CAS on Ach provocation test were enrolled for this study. Those patients were divided into 2 groups according to ECG changes during Ach provocation tests and were analyzed. The study flow chart was shown in Figure 1. We compared the immediate clinical and angiographic characteristics during the Ach provocation test, and cumulative major clinical outcomes up to 5 years in patients with CAS according to presence/absence of ischemic 


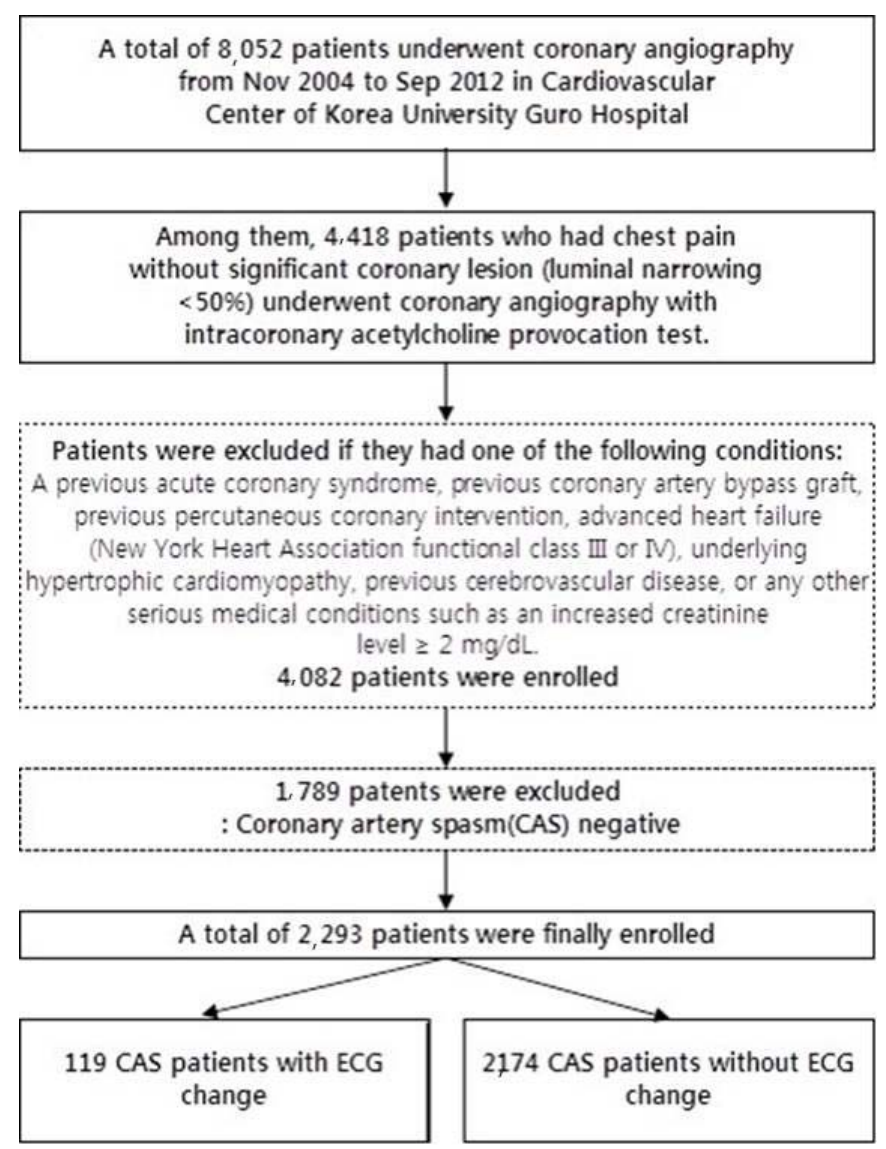

Fig. 1. Study scheme

ECG changes during Ach provocation test. All data were analyzed using the patients' chart review retrospectively. The study protocol conforms to the ethical guidelines of the 1975 Declaration of Helsinki. The research protocol was approved by the ethics committee of the Korea University Guro Hospital

\section{Acetylcholine provocation test}

The first investigations for CAS included typical clinical history, non-invasive stress tests such as treadmill test, ambulatory ECG and stress echocardiography, with subsequent invasive CAG was performed for confirmation. CAS was induced by intracoronary injection of Ach after diagnostic angiography. Nitrates, calcium channel blockers (CCB), beta blockers (BB), angiotensin-converting enzyme inhibitors (ACEI), angiotensin II receptor blocker (ARB) and other vasodilators or vasoconstrictors were withheld at least 72 hours before coronary angiography. Ach was injected by incremental doses of 20 (A1), 50 (A2) and 100 (A3) $\mu \mathrm{g} / \mathrm{min}$ into the left coronary artery over a $1 \mathrm{mi}-$ nute period with 5 minutes intervals to the maximum tolerated dose under continuous monitoring of ECG and blood pressure. Angiography was repeated after each Ach dose. Intracoronary infusion with $0.2 \mathrm{mg}$ nitroglycerine was given after 
completing the Ach provocation test. Angiography was then performed 2 minutes later. If focal or diffuse significant vasoconstriction of coronary arteries was induced with any dose of Ach, the Ach infusion was stopped. End diastolic images for each segment of the left coronary artery were chosen according to the corresponding points on the electrocardiographic trace (QRS onset or end of $\mathrm{T}$ wave) and analyzed using the proper quantitative coronary angiographic system of the catheterization laboratory (FD-20, Phillips, Amsterdam, The Netherlands). The coronary artery diameters were measured with QCA before and after administration of Ach at the site that showed the greatest changes following drug administration. Reference diameter was measured at the proximal and distal portion of each artery before intracoronary Ach infusion and the mean reference diameter was used to assess the diameter narrowing. During the coronary angiography and Ach provocation test, significant CAS was defined as focal or diffuse severe transient luminal narrowing ( > 70\%) with or without chest pain or ischemic ECG change such as ST-T segment elevation, depression ( $\geq 1 \mathrm{~mm}$ ) or T wave inversion, and normal coronary appearance was defined as less than 20\% luminal narrowing on coronary angiogram that was measured with QCA. Myocardial bridge was considered when the characteristic phasic systolic compression of the coronary artery had a $>30 \%$ decrease in diameter on the angiogram after intracoronary nitroglycerin infusion. Multi-vessel spasm (MVS) was defined as spasm of $\geq 2$ major epicardial coronary arteries. The presences of baseline spasm was defined as focal or diffuse narrowing more than $30 \%$ in diameter on the angiogram before the Ach provocation test as compared with the final angiogram after intracoronary nitroglycerin infusion. Diffuse CAS was defined as significant CAS site length $\geq 30 \mathrm{~mm}$. ${ }^{6,7}$

\section{Study definition}

Hypertension was defined as either systolic or diastolic elevation of blood pressure $\geq 140 / 90$ mm Hg or ongoing antihypertensive pharmacological treatment. Dyslipidemia was defined as a total cholesterol level $\geq 200 \mathrm{mg} / \mathrm{dL}$ or current treatment with lipid-lowering drugs. Current smoking was defined as active smoking within the past 12 months. Diabetes mellitus was defined as the fasting blood glucose level $\geq 126 \mathrm{mg} / \mathrm{dL}$, or use of hypoglycemic agents or insulin. Insignificant coronary artery disease was defined the $\leq 20 \%$ diameter stenosis in coronary arteries documented by image studies including computed tomographic angiography, magnetic resonance angiography or invasive angiography. Optimal medical therapy was defined as anti-anginal medications including calcium channel blocker, beta-blocker, trimetazidine, nitrate and if needed, statin would be added on.

\section{Statistical analysis}

All the statistical analyses were performed using SPSS 17.0 (SPSS Inc., Chicago, IL, USA). For continuous variables, differences between two groups 
were evaluated by unpaired t-test or MannWhitney rank test. For discrete variables, differences were expressed as counts and percentages and analyzed with $\chi 2$ or Fisher's exact test between groups as appropriate. Multivariate logistic regression analysis, which included baseline confounding factors, was used for assessing the independent impact factors. Cumulative event proportions were calculated using Kaplan-Meier analyses. A two-tailed $P$-value of $<0.05$ was considered to be statistically significant. Data were expressed as mean \pm standard deviations.

\section{RESULTS}

The baseline clinical characteristics and laboratory findings of patients are shown in Table 1. The most value of age, hypertension, dyslipidemia, smoking history, chronic kidney disease, congenital heart failure were balanced between the two groups. Before the Ach provocation test, CCBs were more frequently prescribed for patients with ECG changes, but the frequency of the use of BBs, ACEIs, ARB, nitrates, and lipid-lowering drugs was similar between the two groups. All patients had normal thyroid function in this study.

The baseline angiographic and ECG changes during the Ach provocation test are shown in Table 2. Before the Ach provocation test, at baseline CAG, the incidence of baseline spasm ( > 30\%) was higher in patients with ischemic ECG changes than in those without ischemic ECG changes. However, the frequency of myocardial bridge was similar between the two groups. Before the Ach provocation test, the reference diameters after NTG infusion were similar between the two groups. During the Ach provocation test, the incidence of significant CAS and Ach-induced ischemic chest pain was higher in patients with ischemic ECG changes.

After Ach infusion, the mean percentage narrowing on QCA was more severe in patients with ischemic ECG changes than in those without ECG changes. Univariate analysis showed that patients with ischemic ECG changes were associated with a higher incidence of baseline spasm, severe spasm, and multivessel involvement, and more diffuse spasms ( > $30 \mathrm{~mm}$ ).

At the 5-year follow-up (mean follow-up duration $2272 \pm 843$ days), the incidence of total death (cardiac death and non-cardiac death rates), major adverse cardiac events (MACE), and major adverse cardiac and cerebral events (MACCE) were higher in patients with ischemic ECG changes than in those without ischemic ECG changes (Table 3).

However, after adjusting for baseline confounding factors including age, sex, hypertension, diabetes, dyslipidemia, current smoking, current alcoholism, myocardial bridge, MVS, and diffuse spastic lesion ( > $30 \mathrm{~mm}$ ) in both the clinical, the cumulative incidence of total death, MACE, and MACCE were higher in patients with ischemic ECG changes at 5 years (Table 4). 
Table 1. Baseline clinical and laboratory characteristics of the study groups.

\begin{tabular}{|c|c|c|c|c|}
\hline Variable, N (\%) & $\begin{array}{c}\text { Total } \\
(n=2293)\end{array}$ & $\begin{array}{l}\text { ECG changes } \\
\qquad(n=119)\end{array}$ & $\begin{array}{l}\text { No changes } \\
(n=2174)\end{array}$ & $P$-Value \\
\hline \multicolumn{5}{|l|}{ Baseline characteristics } \\
\hline Gender (Male) & $1160(50.5)$ & $60(50.4)$ & $1100(50.5)$ & 0.970 \\
\hline Age & $54.6 \pm 11.5$ & $56.7 \pm 11.0$ & $54.4 \pm 11.6$ & 0.151 \\
\hline Body mass index & $24.2 \pm 3.1$ & $24.1 \pm 3.4$ & $24.2 \pm 3.1$ & 0.871 \\
\hline Left ventricular ejection fraction (\%) & $58.2 \pm 4.7$ & $57.0 \pm 5.0$ & $58.3 \pm 4.6$ & 0.138 \\
\hline \multicolumn{5}{|l|}{ Blood pressure; BP } \\
\hline Systolic BP & $135.8 \pm 25.1$ & $134.9 \pm 31.2$ & $135.8 \pm 24.4$ & 0.832 \\
\hline Diastolic BP & $81.7 \pm 14.0$ & $81.5 \pm 14.2$ & $81.7 \pm 13.9$ & 0.923 \\
\hline Heart rate & $71.0 \pm 12.4$ & $70.3 \pm 10.4$ & $71.0 \pm 12.6$ & 0.664 \\
\hline Pulse pressure & $54.0 \pm 17.5$ & $53.4 \pm 22.9$ & $54.1 \pm 16.9$ & 0.818 \\
\hline Hypertension & $1070(46.6)$ & $55(46.2)$ & $1015(46.6)$ & 0.920 \\
\hline Diabetes mellitus & $279(12.1)$ & $11(9.2)$ & $268(12.3)$ & 0.316 \\
\hline Insulin & $45(1.9)$ & $2(1.6)$ & $43(1.9)$ & 1.000 \\
\hline Medication & $199(8.6)$ & $8(6.7)$ & $191(8.7)$ & 0.436 \\
\hline Dyslipidemia & $794(34.6)$ & $38(31.9)$ & $756(34.7)$ & 0.526 \\
\hline Smoking history & 719 (31.3) & $41(34.4)$ & $678(31.1)$ & 0.454 \\
\hline Current smoker & $534(23.2)$ & $35(29.4)$ & $499(22.9)$ & 0.105 \\
\hline Alcoholic history & $867(37.8)$ & $51(42.8)$ & $816(37.5)$ & 0.244 \\
\hline Current alcoholics & $786(34.2)$ & $44(36.9)$ & $742(34.1)$ & 0.524 \\
\hline \multicolumn{5}{|l|}{ Medication history } \\
\hline Beta blocker & $61(2.6)$ & $3(2.5)$ & $58(2.6)$ & 1.000 \\
\hline Angiotensin converting enzyme inhibitor & $28(1.2)$ & $1(0.8)$ & $27(1.2)$ & 1.000 \\
\hline Angiotensin II receptor blocker & $97(4.2)$ & $7(5.8)$ & $90(4.1)$ & 0.358 \\
\hline Nitrate & $445(19.4)$ & $28(23.5)$ & $417(19.1)$ & 0.243 \\
\hline Calcium channel blocker; CCB & $258(11.2)$ & $21(17.6)$ & $237(10.9)$ & 0.023 \\
\hline CCB, not diltiazem & $121(5.2)$ & $9(7.5)$ & $112(5.1)$ & 0.252 \\
\hline Diltiazem & $165(7.1)$ & $14(11.7)$ & $151(6.9)$ & 0.048 \\
\hline Statin & $151(6.5)$ & $9(7.5)$ & $142(6.5)$ & 0.659 \\
\hline \multicolumn{5}{|l|}{ Laboratory findings } \\
\hline Total cholesterol (mg/dL) & $172.6 \pm 40.1$ & $177.8 \pm 39.8$ & $172.1 \pm 40.1$ & 0.346 \\
\hline Triglyceride (mg/dL) & $134.7 \pm 98.0$ & $161.3 \pm 130.3$ & $132.1 \pm 95.0$ & 0.144 \\
\hline $\mathrm{LDL}-\mathrm{C}(\mathrm{mg} / \mathrm{dL})$ & $111.3 \pm 35.8$ & $120.2 \pm 34.4$ & $110.6 \pm 35.9$ & 0.197 \\
\hline $\mathrm{HDL}-\mathrm{C}(\mathrm{mg} / \mathrm{dL})$ & $51.1 \pm 13.3$ & $48.4 \pm 10.4$ & $51.4 \pm 13.6$ & 0.081 \\
\hline Fasting glucose (mg/dL) & $100.7 \pm 22.4$ & $103.3 \pm 17.8$ & $100.5 \pm 22.8$ & 0.410 \\
\hline $\mathrm{HbA1c}(\%$ of Total $\mathrm{Hb}$ ) & $5.9 \pm 0.8$ & $6.0 \pm 0.6$ & $5.9 \pm 0.8$ & 0.444 \\
\hline hsCRP (mg/dL) & $2.5 \pm 7.0$ & $4.2 \pm 9.4$ & $2.4 \pm 6.7$ & 0.118 \\
\hline $\mathrm{ESR}(\mathrm{mm} / \mathrm{hr})$ & $20.4 \pm 28.2$ & $21.6 \pm 23.3$ & $20.3 \pm 28.8$ & 0.801 \\
\hline Protein (g/dL) & $6.9 \pm 0.4$ & $6.9 \pm 0.3$ & $6.9 \pm 0.4$ & 0.767 \\
\hline Albumin (g/dL) & $4.2 \pm 0.3$ & $4.2 \pm 0.3$ & $4.2 \pm 0.3$ & 0.853 \\
\hline
\end{tabular}

Values are mean $\pm \mathrm{SD}$ (range).

ECG, electrocardiogram; LDL, low-density lipoprotein; HDL, high-density lipoprotein; HbA1c, hemoglobin A1c; hsCRP, high sensitivity C-reactive protein; ESR, erythrocyte sedimentation rate. 
Table 2. Baseline angiographic and electrocardiographic changes during Ach provocation test

\begin{tabular}{|c|c|c|c|c|}
\hline Variables, N (\%) & $\begin{array}{c}\text { Total } \\
(\mathrm{n}=2293)\end{array}$ & $\begin{array}{c}\text { ECG changes } \\
(n=119)\end{array}$ & $\begin{array}{l}\text { No changes } \\
(\mathrm{n}=2174)\end{array}$ & $P$-Value \\
\hline Myocardial bridge & $571(24.9)$ & $27(22.6)$ & $544(25.0)$ & 0.566 \\
\hline Baseline spasm (narrowing $30 \%$ ) & $563(24.5)$ & $49(41.1)$ & $514(23.6)$ & $<0.001$ \\
\hline Ach-induced chest pain & $1469(64.0)$ & $91(76.4)$ & $1378(63.3)$ & 0.004 \\
\hline \multicolumn{5}{|l|}{ QCA analysis } \\
\hline Reference diameter after NTG infusion & $2.6 \pm 0.5$ & $2.7 \pm 0.6$ & $2.5 \pm 0.5$ & 0.111 \\
\hline Diameter narrowing after Ach infusion, (mm) & $0.8 \pm 0.3$ & $0.6 \pm 0.3$ & $0.8 \pm 0.3$ & $<0.001$ \\
\hline Diameter narrowing after Ach infusion, (\%) & $69.0 \pm 13.0$ & $77.0 \pm 14.1$ & $68.2 \pm 12.9$ & $<0.001$ \\
\hline QCA, $\langle 50 \%$ & $119(5.1)$ & $4(3.3)$ & $115(5.2)$ & 0.356 \\
\hline QCA, 50-70\% & $889(38.7)$ & $29(24.3)$ & $860(39.5)$ & 0.001 \\
\hline QCA, $>70 \%$ & $1279(55.7)$ & $86(72.2)$ & $1193(54.8)$ & $<0.001$ \\
\hline Multi-vessel spasm & $725(31.6)$ & $60(50.4)$ & $665(30.5)$ & $<0.001$ \\
\hline Diffuse long spasm $(>30 \mathrm{~mm})$ & 1935 (84.3) & $108(90.7)$ & 1827 (84) & 0.049 \\
\hline \multicolumn{5}{|l|}{ Acetylcholine (Ach) dose } \\
\hline Ach 20ug & $119(5.1)$ & $6(5.0)$ & $113(5.2)$ & 0.940 \\
\hline Ach 50ug & $793(34.5)$ & $53(44.5)$ & $740(34.0)$ & 0.019 \\
\hline Ach 100ug & $1380(60.2)$ & $60(50.4)$ & $1320(60.7)$ & 0.025 \\
\hline \multicolumn{5}{|l|}{ ST-T segment change of ECG } \\
\hline STD & $49(2.1)$ & $49(41.1)$ & - & - \\
\hline STE & $44(1.9)$ & $44(36.9)$ & - & - \\
\hline T-inversion & $26(1.1)$ & $26(21.8)$ & - & - \\
\hline AV block & $687(29.9)$ & $33(27.7)$ & $654(30.0)$ & 0.586 \\
\hline Coughing & $630(27.4)$ & $32(26.8)$ & $598(27.5)$ & 0.883 \\
\hline Pacing & $57(2.4)$ & $1(0.8)$ & $56(2.5)$ & 0.365 \\
\hline
\end{tabular}

ECG, electrocardiogram; Ach, acetylcholine; QCA, quantitative coronary angiography; NTG, nitrate; STD, ST segment depression on electrocardiogram; STE, ST segment elevation on electrocardiogram; AV block, atrio-ventricular conduction block.

Table 3. Clinical outcomes at 5-year follow-up.

\begin{tabular}{llccc}
\hline Variables, $\mathbf{N}(\%)$ & $\begin{array}{c}\text { Total } \\
(\mathrm{n}=621)\end{array}$ & $\begin{array}{c}\text { ECG changes } \\
(\mathrm{n}=58)\end{array}$ & $\begin{array}{c}\text { No changes } \\
(\mathrm{n}=563)\end{array}$ & $P$-Value \\
\hline Total death & $6(0.9)$ & $4(6.8)$ & $2(0.3)$ & 0.001 \\
$\quad$ Cardiac death & $2(0.3)$ & $2(3.4)$ & $0(0.0)$ & 0.009 \\
$\quad$ Non-cardiac death & $4(0.6)$ & $2(3.4)$ & $2(0.3)$ & 0.046 \\
PCl & $7(1.1)$ & $0(0.0)$ & $7(1.2)$ & 0.095 \\
Myocardial infarction; Ml & $1(0.1)$ & $1(1.7)$ & $0(0.0)$ & 0.093 \\
Cerebrovascular accidents; CVA & $1(0.1)$ & $0(0.0)$ & $1(0.1)$ & 1.000 \\
Recurrent chest pain (Repeat CAG) & $70(11.2)$ & $6(10.3)$ & $64(11.3)$ & 0.815 \\
MACE & $13(2.0)$ & $4(6.8)$ & $9(1.5)$ & 0.026 \\
MACCE & $14(2.2)$ & $4(6.8)$ & $10(1.7)$ & 0.034 \\
\hline
\end{tabular}

MACE ; Mortality, $\mathrm{PCl}, \mathrm{MI}$

MACCE ; Mortality, PCI, MI, CVA

$E C G$, electrocardiogram; $P C l$, percutaneous coronary intervention; $C A G$, coronary angiography; MACE, major adverse cardiac events ; MACCE, major adverse cardiac and cerebrovascular events. 
Table 4. Univariate and multivariate logistic analyses for clinical outcomes and cumulative clinical outcomes at 5-year follow-up.

\begin{tabular}{lllll}
\hline \multirow{2}{*}{ Variable. N (\%) } & \multicolumn{2}{c}{ Unadjusted } & \multicolumn{2}{c}{ Adjusted } \\
\cline { 2 - 5 } & OR (95\% C.I) & PValue & OR (95\% C.I) & $P$-Value \\
\hline Clinical outcomes at 5years & $19.9(3.6-109.0)$ & 0.001 & $18.9(2.6-135.0)$ & 0.003 \\
$\quad$ Total death & $10.0(1.4-71.6)$ & 0.021 & $11.8(1.3-103.6)$ & 0.025 \\
Cardiac death & - & - & - & - \\
$\quad$ Non-cardiac death & - & - & - & - \\
PCl & - & - & - & - \\
Myocardial infarction; Ml & - & - & - & - \\
Cerebrovascular accidents; CVA & $1.3(0.5-3.2)$ & 0.472 & $1.3(0.5-3.1)$ & 0.534 \\
Recurrent chest pain (Repeat CAG) & $4.4(1.3-14.3)$ & 0.013 & $4.3(1.1-16.1)$ & 0.030 \\
MACE & $3.9(1.2-12.7)$ & 0.019 & $3.5(0.9-12.3)$ & 0.051 \\
MACCE &
\end{tabular}

Adjusted for age, gender (male), hypertension, diabetes mellitus, dyslipidemia, current smokers, current alcoholics, myocardial bridge, multivessel coronary spasm \& diffuse spastic lesion ( $>30 \mathrm{~mm}$ )

\begin{tabular}{|c|c|c|c|c|}
\hline \multirow{2}{*}{ Variable. N (\%) } & \multicolumn{2}{|c|}{ Unadjusted } & \multicolumn{2}{|c|}{ Adjusted } \\
\hline & OR (95\% C.I) & $P$-Value & OR (95\% C.I) & $P$ Value \\
\hline \multicolumn{5}{|l|}{ Cumulative clinical outcomes at 5 years } \\
\hline Total death & $37.0(6.7-202.2)$ & $<0.001$ & $46.8(6.8-321.2)$ & $<0.001$ \\
\hline Cardiac death & $18.6(2.6-132.1)$ & 0.003 & $28.9(3.4-245.4)$ & 0.002 \\
\hline Non-cardiac death & - & - & - & \\
\hline $\mathrm{PCl}$ & - & - & - & - \\
\hline Myocardial infarction; Ml & - & - & - & - \\
\hline Cerebrovascular accidents; CVA & - & - & - & \\
\hline Recurrent chest pain (Repeat CAG) & $1.57(0.7-3.1)$ & 0.194 & $1.46(0.7-2.9)$ & 0.278 \\
\hline MACE & $4.42(1.4-13.4)$ & 0.009 & $3.63(1.1-11.6)$ & 0.030 \\
\hline
\end{tabular}

Adjusted by Age, male, hypertension, diabetes, dyslipidemia, current smokers, current alcoholics, myocardial bridge, multivessel coronary spasm \& diffuse spastic lesion ( $>30 \mathrm{~mm}$ )

MACE ; Mortality, $\mathrm{PCl}, \mathrm{MI}$

MACCE ; Mortality, PCI, MI, CVA

$\mathrm{OR}$, odds ratio; C.I, confidence interval; $\mathrm{PCl}$, percutaneous coronary intervention; CAG, coronary angiography; MACE, major adverse cardiac events ; MACCE, major adverse cardiac and cerebrovascular events.

Kaplan-Meier curves showed that the cumulative incidence of MACE was higher in patients with ischemic ECG changes than in those without ischemic ECG changes at the 5-year follow-up $(4.4 \%$ vs. $1.1 \%$, P log-rank test $=0.004$; $)$ (Fig. 2$)$.

\section{DISCUSSION}

The main findings of the present study are that the patients with ischemic ECG changes during Ach provocation tests were associated with more frequent ischemic chest pain, baseline spasm, diffuse, severe and multi-vessel spasm than patients without ischemic ECG changes and At 5-year follow-up, the incidence of death, MACE and MACCE were higher in the ischemic ECG change group. Therefore, the patients of vasospastic angina showing ischemic ECG change at the time of Ach 


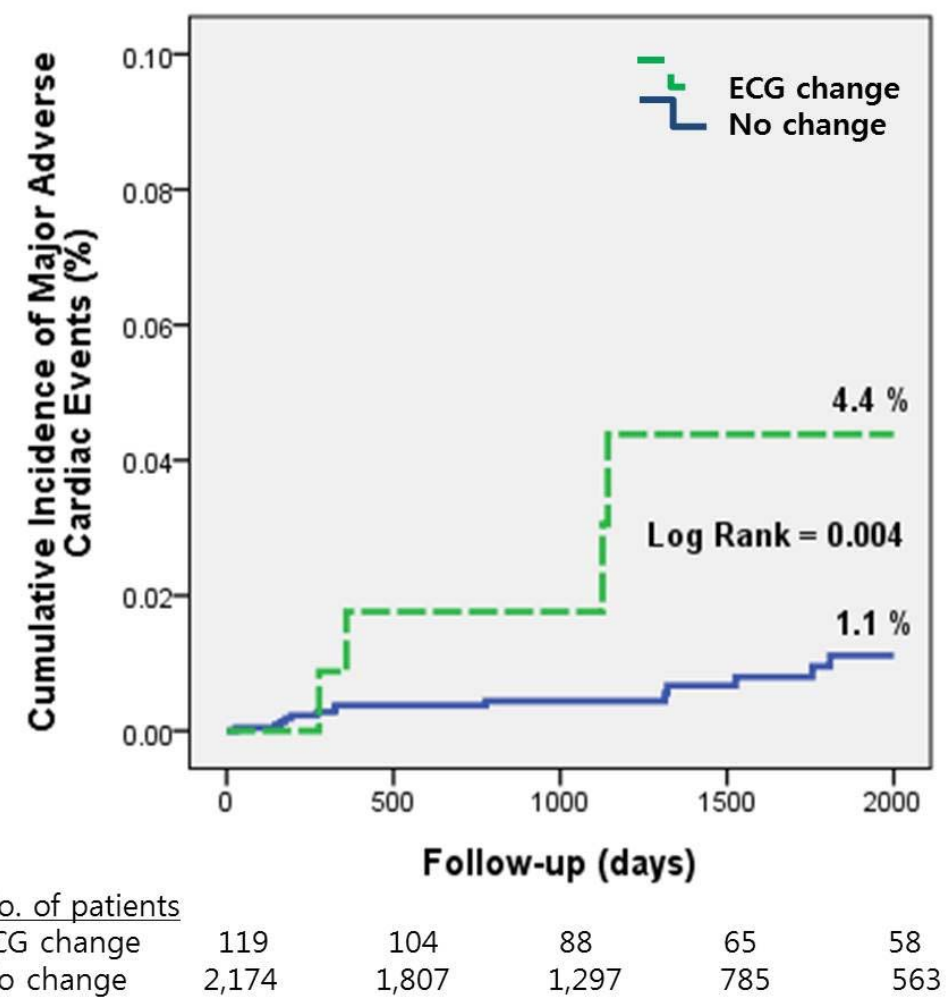

Fig. 2. Kaplan-Meier curves of the cumulative incidence of major adverse cardiac events (\%).

provocation test would require more aggressive and intensive medical therapy would be needed for these particular subset of patients in real world practice.

The Ach challenge can be utilized to evaluate the impairment of coronary vasomotor function including endothelial function ${ }^{8}$ and coronary hyperconstrictive responses after drug-eluting stent (DES) implantation in patients with organic stenosis. ${ }^{9}$ Previous studies also reported that provoked coronary spasm predicts adverse outcomes in patients with acute myocardial infarction (AMI) and there is a high prevalence of a pathological response to Ach testing in patients with stable angina pectoris and unobstructed coronary arteries, suggesting that intracoronary Ach provocation might be a useful and safe clinical tool for the assessment of patients with suspected CAD who are found to have unobstructed coronary arteries. ${ }^{1,10}$ However, clinical significance and angiographic characteristics of patients with vasospastic angina according to the ischemic ECG change during the Ach provocation test are not clarified yet. Ischemic ECG changes may reflect on more significant transient insult in myocardium by transient significant narrowing of coronary arteries induced by Ach infusion. In the present study, we sought to clarify the impact of ischemic ECG changes during Ach provocation test on clinical outcomes in patients with vasospastic an- 
gina up to 5 years.

The commonly associated manifestations of myocardial ischemia due to coronary spasm are typical ischemic chest pain and ST segment changes on ECG. Previous study reported that the ECG changes that occur during the attack of coronary spasm include ST segment elevation (STE) and/or depression (STD), peaking and/or increase in amplitude of the $\mathrm{T}$ wave, a delay in the peak and an increase in the height and width of the $R$ wave resulting in fusion of $R$ wave with $T$ wave, and a decrease in magnitude or disappearance of the S wave. ${ }^{11}$ In the present study, total 119 patients (5.2\%) showed ECG changes during Ach provocation tests. The incidence of ischemic ECG changes are relative infrequent because we immediately reversed the CAS by intracoronary nitroglycerin injection regardless of Ach dose once the Ach response showed significant ( > 70\% narrowing) for patient's safety. If we wait longer time and increase Ach dose, the incidence of ischemic ECG changes would be higher.

A total of 44 patients (36.9\%) with STD and 49 patients (41.1\%) with STE on ECG were noted in the ECG change group. Previous study reported that sequential and simultaneous multiple spasm were more frequently associated with serious arrhythmias, such as ventricular bigeminy or complete AV block. ${ }^{12}$ In the present study, multi-vessel spasm was higher in the ECG change group (50.4\% vs. $30.5 \%, P<0.001)$. However, there was no difference of AV block on ECG during Ach provocation between the two groups.
It was often preceded by ischemic ECG changes and/or reproduction of the symptoms of the patient, suggesting that epicardial spasm often began with microvascular spasm. ${ }^{1,13}$ This indicates that there is a spectrum of coronary vasomotion in response to Ach ranging from subtle changes compatible with microvascular spasm to severe distal and diffuse epicardial spasm, consistent with locally exaggerated responses to the vasoconstrictive stimuli, in which endothelial dysfunction and superimposed local hyperreactivity of vascular smooth muscles may be present. ${ }^{6,7}$

The variability of the overall response to Ach as a function of the infused dose and of the coronary segment may be explained by local variations in the balance between its opposing vasomotor effects, which means that vasodilation caused by endothelial release of endothelium-derived relaxing factor (EDRF), and vasoconstriction caused by direct stimulation of vascular smooth muscle. It has been suggested that constriction of atherosclerotic epicardial vessels in response to intracoronary Ach is paradoxical and indicative of wide spread endothelial dysfunction. ${ }^{14,15}$ In the present study, after Ach infusion, mean \% narrowing and minimal luminal diameter $(\mathrm{mm})$ by QCA were more severe in the ECG change group, and the ECG change group also showed more frequent Ach induced chest pain during the Ach provocation test, suggesting that angiographic and clinical characteristics during Ach provocation test in the ECG change group were worse than those of no ECG change group. Therefore, the ECG 
change group during Ach provocation test should require more aggressive medical treatment with anti-anginal agents and close clinical observation.

It is noteworthy that patients with ischemic ECG changes in whom severe CAS were observed received more antianginal medications such as CCBs (17.6\%), than did those without ECG changes (10.9\%), empirically based on the outpatient clinics (Table 1). A recent study reported increased basal tone and hyper-responsiveness to Ach and ergonovine in spasm related coronary arteries in patients with vasospastic angina. ${ }^{16}$ In our study, the ECG change group also showed more basal spasm (41.1\%) than the no ECG change group, which suggest that basal coronary artery tone is increased in patients with vasospastic angina with higher disease activity at the spasm related artery and this may be related to the occurrence of CAS. ${ }^{17,18}$

In the context, we tested the hypothesis that the ECG change group might have worse clinical outcomes in the long-term follow-up compared to the no ECG change group in patients with vasospastic angina. At 5-year follow-up, the incidence of total death $(6.8 \%$ vs. $0.3 \%, P=0.001)$ and cardiac death $(3.4 \%$ vs. $0 \%, P=0.009)$ were higher in the ECG change group. The incidence of MACE (6.8\% vs. $1.5 \%, P=0.026)$ and MACCE composite of death, PCI, MI, CVA (6.8\% vs. $1.7 \%, P=0.034)$ were higher in the ECG change group (Table 3). Although the precise mechanisms for the worse clinical outcomes of patients with the ischemic ECG changes during Ach provocation test remain to be elucidated, these findings supported that the ischemic ECG changes during Ach provocation test may have potential to predict cardiac events in patients with vasospastic angina in the long-term follow-up period. To our knowledge, this is the first study investigated the long-term clinical outcomes of vasospastic angina patients according to the presence/absence of ischemic ECG changes during Ach provocation test.

This study has several obvious limitations. First, this is an observational retrospective design, which lacks randomization and may introduce a selection bias. Second, even though we minimized the confounding effects from the baseline biases with multivariate logistic analysis, it is possible that some potential confounders might have crept in. However, we tested CAS in relatively larger study population, which helpful in minimizing the confounding effects from the baseline biases. Third, Ach provocation test was not performed in the early morning. Circadian variation of CAS may ${ }^{19}$ be the reason why the provocation rate for coronary spasm in patients with variant angina was lower in our study than that in the previous report. ${ }^{20}$ Fourth, in the guideline for diagnosis and treatment of patients with vasospastic angina [Japaneses coronary association (JCS) 2008], CAS was defined as "transient, total, or sub-total occlusion ( $>$ 90\% stenosis) of a coronary artery with sign/symptoms of myocardial ischemia (anginal pain and ischemic ST changes). ${ }^{21}$ However, we considered the patients' safety and convenience in real world clinical practice because we did Ach provocation test on the base of outpatients' clinic 
and used $4 \mathrm{~F}$ transradial approach. Therefore, in our study, significant CAS was defined as focal or diffuse severe transient luminal narrowing ( $>$ 70\%) with or without chest pain or ischemic ECG change such as ST-T segment elevation, depression ( $\geq 1 \mathrm{~mm}$ ) or $\mathrm{T}$ wave inversion. Fifth limitation is the study population in whom there may have been bias toward those who underwent the Ach provocation tests. Ach provocation tests were performed to document vasospasm for the diagnosis of vasospastic angina. Thus, this study was not designed to evaluate the degree of endothelial dysfunction in patients with variant angina prospectively. Therefore, further study is necessary to investigate the pathophysiology of spasms induced by Ach in patients with vasospastic angina. Sixth, because we enrolled the all patients who had chest pain (not concern about typical or atypical) without significant coronary artery stenosis, usual expected $(+)$ rate of spasm might be higher in this study. This result could be happened. Therefore, we enrolled just $>70 \%$ diffuse coronary spasm which is not regarded as vasospastic angina currently.

In conclusion, the patients with ischemic ECG changes during the Ach provocation tests were associated with more frequent chest pain, baseline spasm, diffuse, severe and multi-vessel spasm than patients without ischemic ECG changes. At 5-year follow-up, the incidence of death, MACE and MACCE were higher in the ECG change group. Therefore, in real world, the patients of vasospastic angina with ischemic ECG changee during
Ach provocation test would require more aggressive and intensive medical therapy and careful clinical follow-up would be needed for these particular subsets of patients.

\section{REFERENCES}

1. Ong P, Athanasiadis A, Borgulya G, Mahrholdt H, Kaski JC, Sechtem U. High prevalence of a pathological response to acetylcholine testing in patients with stable angina pectoris and unobstructed coronary arteries. The ACOVA Study (Abnormal COronary VAsomotion in patients with stable angina and unobstructed coronary arteries). J Am Coll Cardiol 2012;59:655-62.

2. Douglas PS, Patel MR, Bailey SR, Dai D, Kaltenbach L, Brindis RG, et al. Hospital variability in the rate of finding obstructive coronary artery disease at elective, diagnostic coronary angiography. J Am Coll Cardiol 2011;58:801-9.

3. Johnston N, Schenck-Gustafsson K, Lagerqvist B. Are we using cardiovascular medications and coronary angiography appropriately in men and women with chest pain? Eur Heart J 2011;32:1331-6.

4. Takagi Y, Yasuda S, Takahashi J, Tsunoda R, Ogata Y, Seki A, et al. Clinical implications of provocation tests for coronary artery spasm: safety, arrhythmic complications, and prognostic impact: multicentre registry study of the Japanese Coronary Spasm Association. Eur Heart J 2013;34:258-67. 
5. el-Tamimi H, Davies GJ, Crea F, Maseri A. Response of human coronary arteries to acetylcholine after injury by coronary angioplasty. J Am Coll Cardiol 1993;21:1152-7.

6. Im SI, Rha SW, Choi BG, Choi SY, Kim SW, Na JO, et al. Angiographic and clinical characteristics according to intracoronary acetylcholine dose in patients with myocardial bridge. Cardiology 2013;125:250-7.

7. Im SI, Choi WG, Rha SW, Choi BG, Choi SY, Kim SW, et al. Significant response to lower acetylcholine dose is associated with worse clinical and angiographic characteristics in patients with vasospastic angina. Korean Circ J 2013;43:468-73.

8. Summers MR, Lerman A, Lennon RJ, Rihal CS, Prasad A. Myocardial ischaemia in patients with coronary endothelial dysfunction: insights from body surface ECG mapping and implications for invasive evaluation of chronic chest pain. Eur Heart J 2011;32:2758-65.

9. Obata JE, Kitta Y, Takano H, Kodama Y, Nakamura T, Mende A, et al. Sirolimus-eluting stent implantation aggravates endothelial vasomotor dysfunction in the infarct-related coronary artery in patients with acute myocardial infarction. J Am Coll Cardiol 2007;50:1305-9.

10. Wakabayashi K, Suzuki H, Honda Y, Wakatsuki D, Kawachi K, Ota K, et al. Provoked coronary spasm predicts adverse outcome in patients with acute myocardial infarction: a novel predictor of prognosis after acute myocardial infarction. J Am Coll Cardiol 2008;52:518-22.

11. Yasue H, Nakagawa H, Itoh T, Harada E, Mizuno
Y. Coronary artery spasm---clinical features, diagnosis, pathogenesis, and treatment. J Cardiol 2008;51:2-17.

12. Onaka H, Hirota Y, Shimada S, Kita Y, Sakai Y, Kawakami Y, et al. Clinical observation of spontaneous anginal attacks and multivessel spasm in variant angina pectoris with normal coronary arteries: evaluation by 24-hour 12-lead electrocardiography with computer analysis. J Am Coll Cardiol 1996;27:38-44.

13. Ohba K, Sugiyama S, Sumida H, Nozaki T, Matsubara J, Matsuzawa Y, et al. Microvascular coronary artery spasm presents distinctive clinical features with endothelial dysfunction as nonobstructive coronary artery disease. J Am Heart Assoc 2012;1:e002485.

14. Newman CM, Maseri A, Hackett DR, el-Tamimi HM, Davies GJ. Response of angiographically normal and atherosclerotic left anterior descending coronary arteries to acetylcholine. Am J Cardiol 1990;66:1070-6.

15. Ludmer PL, Selwyn AP, Shook TL, Wayne RR, Mudge GH, Alexander RW, et al. Paradoxical vasoconstriction induced by acetylcholine in atherosclerotic coronary arteries. N Engl J Med 1986;315:1046-51

16. Lee SJ, Park SJ, Park SW, Kim JJ, Song JK, Hong $\mathrm{MK}$, et al. Increased basal tone and hyperresponsiveness to acetylcholine and ergonovine in spasm-related coronary arteries in patients with variant angina. Int J Cardiol 1996;55:117-26.

17. Kaski JC, Maseri A, Vejar M, Crea F, Hackett D. Spontaneous coronary artery spasm in variant 
angina is caused by a local hyperreactivity to a generalized constrictor stimulus. J Am Coll Cardiol 1989;14:1456-63.

18. Kuga $\mathrm{T}$, Egashira $\mathrm{K}$, Inou $\mathrm{T}$, Takeshita $\mathrm{A}$. Correlation of basal coronary artery tone with constrictive response to ergonovine in patients with variant angina. J Am Coll Cardiol 1993;22:144-50.

19. Yasue H, Omote S, Takizawa A, Nagao M, Miwa K, Tanaka S. Circadian variation of exercise capacity in patients with Prinzmetal's variant angi- na: role of exercise-induced coronary arterial spasm. Circulation 1979;59:938-48.

20. Okumura K, Yasue H, Matsuyama K, Goto K, Miyagi H, Ogawa H. Sensitivity and specificity of intracoronary injection of acetylcholine for the induction of coronary artery spasm. J Am Coll Cardiol 1988;12:883-8.

21. JCS Joint Working Group. Guidelines for diagnosis and treatment of patients with vasospastic angina (coronary spastic angina) (JCS 2008): digest version. Cir J 2010;74:1745-62. 